\title{
Malignant hyperthermia
}

\author{
Michael P Phy DO
}

\begin{abstract}
Malignant hyperthermia is a rare metabolic crisis triggered by volatile anesthetics and/or succinylcholine. It is important to remember that hyperthermia is not always present and may even present late in the course. Early recognition of the most common signs and symptoms is critical to diagnosis and treatment. Malignant hyperthermia was associated with a high mortality rate, but this has decreased with the use of dantrolene. Although this is frequently reported in the anesthesia and surgical literature, it is important that critical care units that use succinylcholine as part of their intubation sequence be prepared to identify and treat this serious syndrome.
\end{abstract}

Key words: malignant hyperthermia, succinylcholine, muscle injury, rigidity

\section{INTRODUCTION}

Malignant hyperthermia is a rare metabolic crisis triggered by volatile anesthetics and/or succinylcholine. It has been associated with a high mortality rate, but this has decreased with the use of dantrolene.

\section{CASE}

A 23-year-old African-American man was admitted to undergo a left elbow ganglion cyst removal. The patient had no previous history of medical problems and was on no medications. His only procedural history was removal of wisdom teeth about 5 months prior to this admission which was uneventful. His pre-anesthetic evaluation was completed, and no concerns were found, including questions about

Corresponding author: Michael P Phy DO

Contact Information: micheal.phy@ttuhsc.edu

DOI: 10.12746/swrccc2016.0413.173 a personal or family history of anesthetic problems or malignant hyperthermia $(\mathrm{MH})$.

Induction anesthesia included propofol, fentanyl, and succinylcholine. The patient became extremely rigid immediately after the injection of the medications. Rigidity was noted in the masseter muscles and upper extremities but was most pronounced in the lower extremities. Vital signs at that time showed a sharp increase in core temperature from 94.1 to $97^{\circ} \mathrm{F}$, blood pressure $140 / 88 \mathrm{mmHg}$, and a heart rate 90 beats/minute. End-tidal $\mathrm{PCO}_{2}$ level was $62 \mathrm{mmHg}$, and oxygen saturation was $98 \%$. Rapid ventilation was initiated by the anesthesiologist. All spasms subsided in five minutes, and the $\mathrm{PaCO}_{2}$ decreased to $30-36 \mathrm{mmHg}$. The patient's core temperature also decreased to $95^{\circ} \mathrm{F}$.

The decision to continue with the surgery was made by the surgical and anesthetic staff. Anesthesia with propofol and narcotics was continued. The procedure lasted thirty minutes. Vital signs, including 
temperature and $\mathrm{PaCO}_{2}$, remained within normal limits for the duration of the procedure. No inhaled anesthetics were ever used during the case. The patient was extubated without difficulty and remained stable in the post-anesthesia recovery unit. Results of the intra-operative labs revealed an elevated creatine kinase (CK) of 2,107 U/L (normal 60-305 U/L), normal potassium $(4.2 \mathrm{mmol} / \mathrm{L})$, and normal creatinine $(0.9 \mathrm{mg} / \mathrm{d})$. There were no abnormal values on the complete blood count. Post-operative ECG showed a normal sinus rhythm with no ST-T wave abnormalities and no conduction abnormalities.

In the immediate post-operative setting the anesthesiologist called the Malignant Hyperthermia Hotline and reported the case to the on-call physician. It was determined the case was consistent with $\mathrm{MH}$, and a recommendation was given to start dantrolene. The patient was given $2.5 \mathrm{mg} / \mathrm{kg}$ as his initial dose. The patient was transferred to the MICU. Upon arrival, the patient was somnolent but alert. He denied chest pain, shortness of breath, and myofascial pain. Additional medical history included a history of infrequent alcohol use but no illicit drugs. His family history revealed sudden death in his mother at age 52 of unknown causes. He was not aware of any family history of $\mathrm{MH}$ or anesthetic issues. During this time, medical staff contacted one of the patient's sisters who confirmed that the patient's maternal grandmother had a previous episode thought to be $\mathrm{MH}$. Vital signs in the MICU showed temperature $96.6^{\circ} \mathrm{F}$, blood pressure $136 / 84 \mathrm{mmHg}$, heart rate 74 beats/minute, and respiratory rate 16 breaths/minute. Laboratory tests four hours after the initial results revealed a rising CK at $3151 \mathrm{U} / \mathrm{L}$. All other hematologic and electrolyte levels remained normal. Urine myoglobin was negative. Intravenous fluids were changed to $0.9 \%$ normal saline at $150 \mathrm{ml} /$ hour. After the loading dose of dantrolene, it was ordered $1 \mathrm{mg} / \mathrm{kg}$ IV every six hours. On post-operative day one, the patient's vital signs remained normal, and his highest recorded temperature was $98.3^{\circ} \mathrm{F}$. Electrolytes were normal, but the CK had increased to 3817 U/L. Four doses of IV dantrolene were completed by the evening of that day. On post-operative day 2 the patient remained stable; vital signs, temperature, and electrolytes remained normal. The CK had declined to $3764 \mathrm{U} / \mathrm{L}$. No further dantrolene was administered, and the patient was discharged. He never manifested myofascial symptoms. Four days after discharge the $\mathrm{CK}$ had decreased to $1198 \mathrm{U} / \mathrm{L}$, and one week after surgery the level had decreased to $534 \mathrm{U} / \mathrm{L}$. He restarted physical activity twelve days after surgery and participated in a full football season without sequelae.

\section{Discussion}

Malignant hyperthermia $(\mathrm{MH})$ is a hypermetabolic crisis that occurs when an $\mathrm{MH}$ susceptible individual is exposed to a volatile anesthetic agent or succinylcholine. Examples of volatile agents include halothane, isoflurane, enflurane, sevoflurane, and desflurane. ${ }^{1-5}$ The incidence of $\mathrm{MH}$ in the general population is estimated at 1 cases per 100,000 administered anesthetics. ${ }^{6}$ Approximately $50 \%$ of patients who develop acute $\mathrm{MH}$ have had one or two uneventful exposures to triggering agents. ${ }^{7,8}$ Malignant hyperthermia occurs in all ethnic groups. Reactions occur more frequently in males than females $(2: 1)$. Children less than 19 years account for about 50 percent of the reported cases. ${ }^{7,9}$ Historically, mortality related to $\mathrm{MH}$ has been high (1-17\%), but the use of dantrolene has significantly reduced the mortality rate. ${ }^{5,6}$ The Malignant Hyperthermia Association of the United States (MHAUS) receives approximately 100 cases of $\mathrm{MH}$ per year and reports one to two deaths every one to two years, approximating a mortality of $0.5 \%$.

$\mathrm{MH}$ susceptible patients have genetic skeletal muscle receptor abnormalities, allowing excessive calcium accumulation in the presence of certain anesthetic triggering agents. ${ }^{4,5,10}$ During an episode of $\mathrm{MH}$, the clinical manifestations are due to cellular hypermetabolism, leading to sustained muscular contraction and breakdown (rhabdomyolysis), anaerobic metabolism, acidosis, and their sequelae. The majority of $\mathrm{MH}$ susceptible patients have mutations encoding for abnormal ryanodine receptors (RYR1) or dihy- 
dropiridine receptors. Exposure to triggering agents in these patients may lead to unregulated release of calcium from the sarcoplasmic reticulum into the cytoplasm, leading to an acute $\mathrm{MH}$ crisis. ${ }^{11-20}$

An increase in aerobic metabolism during a $\mathrm{MH}$ crisis can sustain the muscle integrity for some time, but there is an eventual increase in carbon dioxide production which leads to cellular acidosis. This is accompanied by depletion of oxygen and adenosine triphosphate..$^{21-23}$ This leads to the early signs of $\mathrm{MH}$ which are hypercarbia and mixed respiratory/metabolic acidosis. The anaerobic metabolism worsens acidosis with the production of lactate. Energy stores are eventually depleted, and rhabdomyolysis occurs, often leading to hyperkalemia and myoglobinuria. Over time, the sustained muscle contractions generate more heat than the body can dissipate. Hyperthermia may occur minutes to hours following the onset of symptoms. Severe hyperthermia (up to $45^{\circ} \mathrm{C}\left[113^{\circ} \mathrm{F}\right]$ ) can cause multiple organ failure and disseminated intravascular coagulation, a poor prognostic indicator and often terminal event. ${ }^{24}$

Volatile anesthetics potentiate sarcoplasmic calcium release in $\mathrm{MH}$ susceptible patients. Succinylcholine is an analog of acetylcholine and stimulates the motor endplate to initiate muscle depolarization, which can become sustained in these patients as well. The only known therapy for $\mathrm{MH}$, dantrolene, binds to the RYR1 receptor to inhibit the release of calcium from the sarcoplasmic reticulum; this reverses the negative cascade of effects. ${ }^{25-27}$ The great majority of $\mathrm{MH}$ cases have occurred when the patient received a volatile anesthetic agent with or without administration of succinylcholine. ${ }^{7}$ Malignant hyperthermia has been reported following administration of succinylcholine (as in our case) in the absence of an inhalational agent (e.g., to facilitate endotracheal intubation).

The clinical manifestations of $\mathrm{MH}$ vary but typically include hypercarbia, sinus tachycardia, and masseter or generalized muscle rigidity. ${ }^{7,29}$ The most common initial sign is an unexpected rise in end-tidal carbon dioxide $\left(\mathrm{ETCO}_{2}\right)$, which is difficult to decrease as minute ventilation is increased. Generalized muscle rigidity in the presence of neuromuscular blockade is virtually pathognomonic for $\mathrm{MH}$ when other signs are present. Most patients with $\mathrm{MH}$ do not develop all signs, but they typically present in a similar order: masseter spasm/generalized muscle rigidity, hypercarbia, sinus tachycardia, tachypnea, cyanosis, rapidly increasing temperature, and elevated temperature. Other signs that may follow include sweating, ventricular tachycardia, dark urine, ventricular fibrillation, and excessive bleeding. ${ }^{7}$ There is a widespread misconception that $\mathrm{MH}$ begins with hyperthermia as the presenting sign. Hyperthermia is generally a late sign of $\mathrm{MH}$ and is typically absent when the diagnosis is initially suspected. In a study of 255 patients, rapidly increasing or inappropriately elevated temperature was one of the first signs in 8.2 percent of $\mathrm{MH}$ crises and was the sole initial sign in only 3.9 percent.

In the acute setting, the diagnosis of $\mathrm{MH}$ should be based on the presence of one or more of the typical clinical manifestations. The diagnosis must be considered in all patients receiving triggering agents, because over 90 percent of patients developing acute $\mathrm{MH}$ have a negative family history for $\mathrm{MH}$, and over half have had uneventful general anesthetics in the past. ${ }^{7}$ Laboratory findings are not required for a presumptive diagnosis. Studies that support the diagnosis include a $\mathrm{pH}$ of $<7.25$, serum potassium $>6$ $\mathrm{mEq} / \mathrm{L}$, elevated $\mathrm{CK}$, and an elevated serum and/or urine myoglobin.

After the initial signs or symptoms are noticed, treatment of $\mathrm{MH}$ should be started. Operating suites or other medical venues that use succinylcholine, such as intensive care units, should have an appropriately stocked $\mathrm{MH}$ treatment cart as recommended by the Malignant Hyperthermia Association of the United States (MHAUS) (http://mhaus.org/faqs/stocking-an-mh-cart). Assistance with the $\mathrm{MH}$ diagnosis is available from the MHAUS Hotline at 1-800-644-9737 in the United States $(00+1+209+417+3722$ outside 
the United States). Important keys are to increase oxygenation and ventilation, discontinue any triggering agent (volatile anesthetic or succinylcholine), and administer dantrolene. Dantrolene is the only known antidote for $\mathrm{MH}$ and is given with a loading dose of $2.5 \mathrm{mg} / \mathrm{kg}$ intravenously. Subsequent boluses of 1 $\mathrm{mg} / \mathrm{kg}$ should be given every 4-6 hours for at least 24 hours. Dantrolene usually works within minutes, and the end tidal carbon dioxide levels decrease first. Patients should be transferred and monitored in an intensive care unit for at least 24 hours for hemodynamic monitoring, ventilatory support (as needed), and frequent laboratory testing. Dantrolene infusions should be continued for at least 24 hours or continued until signs and symptoms have resolved. Dantrolene may be stopped if all of the following criteria are met: metabolic stability for 24 hours, core temperature less than $38^{\circ} \mathrm{C}$, creatinine kinase decreasing, no evidence of myoglobinuria, and no muscle rigidity.

Author Affiliation: Michael P Phy is a general internist in the Department of Internal Medicne at Texas Tech University Health Sciences Center in Lubbock, TX.

Received: $12 / 23 / 2015$

Accepted: 01/11/2016

Reviewers: Cynthia Jumper MD

Published electronically: 01/15/2016

Conflict of Interest Disclosures: none

\section{REFERENCES}

1. Denbrough MA, Forster JF, Lovell RR, et al. Anaesthetic deaths in a family. Br J Anaesth 1962; 34:395.

2. Denborough M. Malignant hyperthermia. Lancet 1998; 352:1131.

3. Rosenberg H, Fletcher JE. International Malignant Hyperthermia Workshop and Symposium, Hiroshima, Japan, July 16-19,
1994. 82, 803-805. 1995.

4. MacLennan DH, Phillips MS. Malignant hyperthermia. Science 1992; 256:789.

5. Wappler F. Malignant hyperthermia. Eur J Anaesthesiol 2001; 18:632.

6. Brady JE, Sun LS, Rosenberg H, Li G. Prevalence of malignant hyperthermia due to anesthesia in New York State, 20012005. Anesth Analg 2009; 109:1162.

7. Larach MG, Gronert GA, Allen GC, et al. Clinical presentation, treatment, and complications of malignant hyperthermia in North America from 1987 to 2006. Anesth Analg 2010; 110:498. 8. Bendixen D, Skovgaard LT, Ording H. Analysis of anaesthesia in patients suspected to be susceptible to malignant hyperthermia before diagnostic in vitro contracture test. Acta Anaesthesiol Scand 1997; 41:480.

9. Rosenberg H, Davis M, James D, et al. Malignant hyperthermia. Orphanet J Rare Dis 2007; 2:21.

10. Lee-Chiong TL Jr, Stitt JT. Disorders of temperature regulation. Compr Ther 1995; 21:697.

11. O'Sullivan GH, McIntosh JM, Heffron JJ. Abnormal uptake and release of $\mathrm{Ca}^{2+}$ ions from human malignant hyperthermiasusceptible sarcoplasmic reticulum. Biochem Pharmacol 2001; 61:1479.

12. Berchtold MW, Brinkmeier H, Müntener M. Calcium ion in skeletal muscle: its crucial role for muscle function, plasticity, and disease. Physiol Rev 2000; 80:1215.

13. Ohnishi ST, Taylor S, Gronert GA. Calcium-induced $\mathrm{Ca}^{2+}$ release from sarcoplasmic reticulum of pigs susceptible to malignant hyperthermia. The effects of halothane and dantrolene. FEBS Lett 1983; 161:103.

14. Struk A, Lehmann-Horn F, Melzer W. Voltage-dependent calcium release in human malignant hyperthermia muscle fibers. Biophys J 1998; 75:2402.

15. Vilven J, Coronado R. Opening of dihydropyridine calcium channels in skeletal muscle membranes by inositol trisphosphate. Nature 1988; 336:587.

16. Wappler F, Scholz J, Köchling A, et al. Inositol 1,4,5-trisphosphate in blood and skeletal muscle in human malignant hyperthermia. Br J Anaesth 1997; 78:541.

17. Stewart SL, Hogan K, Rosenberg H, Fletcher JE. Identification of the $\operatorname{Arg} 1086 \mathrm{His}$ mutation in the alpha subunit of the voltage-dependent calcium channel (CACNA1S) in a North American family with malignant hyperthermia. Clin Genet 2001; 59:178.

18. Quane KA, Healy JM, Keating KE, et al. Mutations in the ryanodine receptor gene in central core disease and malignant hyperthermia. Nat Genet 1993; 5:51.

19. Censier K, Urwyler A, Zorzato F, Treves S. Intracellular calcium homeostasis in human primary muscle cells from malignant hyperthermia-susceptible and normal individuals. Effect Of 
overexpression of recombinant wild-type and Arg163Cys mutated ryanodine receptors. J Clin Invest 1998; 101:1233.

20. Sambuughin N, Holley H, Muldoon S, et al. Screening of the entire ryanodine receptor type 1 coding region for sequence variants associated with malignant hyperthermia susceptibility in the North American population. Anesthesiology 2005; 102:515.

21. Gronert GA, Theye RA. Halothane-induced porcine malignant hyperthermia: metabolic and hemodynamic changes. Anesthesiology 1976; 44:36.

22. Mickelson JR, Louis CF. Malignant hyperthermia: excitation-contraction coupling, $\mathrm{Ca}^{2+}$ release channel, and cell $\mathrm{Ca}^{2+}$ regulation defects. Physiol Rev 1996; 76:537.

23. Louis CF, Zualkernan K, Roghair T, Mickelson JR. The effects of volatile anesthetics on calcium regulation by malignant hyperthermia-susceptible sarcoplasmic reticulum. Anesthesiology 1992; 77:114.

24. Nelson TE. Porcine malignant hyperthermia: critical temperatures for in vivo and in vitro responses. Anesthesiology 1990; 73:449.

25. Paul-Pletzer $\mathrm{K}$, Yamamoto $\mathrm{T}$, Bhat $\mathrm{MB}$, et al. Identification of a dantrolene-binding sequence on the skeletal muscle ryanodine receptor. J Biol Chem 2002; 277:34918.

26. Harrison GG. Control of the malignant hyperpyrexic syndrome in MHS swine by dantrolene sodium. Br J Anaesth 1975; 47:62.

27. Kolb ME, Horne ML, Martz R. Dantrolene in human malignant hyperthermia. Anesthesiology 1982; 56:254.

28. Riazi S, Larach MG, Hu C, et al. Malignant hyperthermia in Canada: characteristics of index anesthetics in 129 malignant hyperthermia susceptible probands. Anesth Analg 2014; 118:381. 29. Larach MG, Localio AR, Allen GC, et al. A clinical grading scale to predict malignant hyperthermia susceptibility. Anesthesiology 1994; 80:771.

30. Burkman JM, Posner KL, Domino KB. Analysis of the clinical variables associated with recrudescence after malignant hyperthermia reactions. Anesthesiology 2007; 106:901. 